Factors that Aid in the Promotion and Retention of Engineering Technology Faculty

\author{
Nicholas Akinkuoye ${ }^{1}$, Ph.D. \\ Associate Professor of Manufacturing Engineering \\ Cuyahoga Community College \\ College of Engineering \\ 2900 Community College Avenue \\ Cleveland, $\mathrm{OH} 44115$ \\ Tel. (216)987-4602
}

Olusegun Odesina, Ph.D.

Associate Professor of Industrial Technology

Department of Industrial Technology

Central Connecticut State University

New Britain, CT 06050

${ }^{1}$ Corresponding Author

February 9, 1998 


\section{Factors that Aid in the Promotion and Retention of Engineering Technology Faculty}

\section{Introduction}

Numerous national surveys and scholarly studies indicate that significant changes have taken place involving retention, tenure and promotion practices at colleges and universities in the past ten years (Blackburn, O’Connell, \& Pellino, 1980; Bowen \& Schuster, 1986; Miller, 1988). Retention, tenure and promotion are the most visible and prominent faculty management tools in colleges and universities today. As such, they have a profound effect on individuals, departments and the profession. How can Industrial Technology Education and others be helped in their retention endeavors? Although this study used Industrial Technology educators as subjects, it also has implications for the engineering profession.

\section{Retention Status}

Some research studies have focused on tenure and promotion in light of practices, changing expectations and requirement. However, no studies have addressed the factors that may actually aid individuals to excel in their job performance, thus contributing to retention status through tenure and promotion. Peers generally consider tenure and promotion a crossroad for faculty members seeking professional recognition. It appears that faculty are working longer hours to meet increased expectations and many are finding it difficult to perform well in the areas of teaching and service while excelling in the area of scholarship. In addition, faculty may be expected to modify their personal values and set priorities that are congruent with more rigorous standards to earn tenure or be promoted (Israel \& Baird, 1988).

Sanders (1988) reported that the Industrial Education field is beginning to feel the repercussions of present trends in tenure denial. It is more difficult to achieve tenure now than in 
the past. Sanders has noted that many talented young professionals have decided not to pursue careers in higher education because of the increasing expectations for tenure and promotion.

"No other aspect of a college educator's professional life demands as much attention as this issue, yet, if tenure and promotion are treated in a cavalier manner the faculty member becomes the victim" (Duff, 1988, p. 70). The decision not to retain, promote or tenure an individual has implications not only for the present but it also has consequences lasting far into the future. The fate of an individual's career and that of college and university programsindeed, professional society—rests on this important decision.

Retention, tenure and promotion practices vary widely throughout the United States because higher education traditions are characterized by vast differences. In addition, expectations regarding retention, tenure and promotion vary considerably, and the process also varies within colleges and universities. Some institutions use committees; others do not. The criteria usually are teaching, service and research but not necessarily in this order. Kasten (1984) reported that teaching was second in importance to research in most institutions, and faculty "overwhelmingly agree that service has almost no importance in tenure decisions" (p. 507). The criteria may depend on the primary focus of an institution as many schools are not research based.

Bjorkquist (1988) remarked that it is counterproductive to recruit individuals for tenuretrack positions if they do not have the potential to achieve tenure and be promoted. To be truly committed to retention, tenure and promotion of faculty, there needs to be clear communication of what criteria and standards are necessary to be successful. Jones, Casali and Green (1985) emphasized that the optimum time to determine the degree of match or mismatch is during a prospective faculty member's interviewing process, not several years into a career. 
In addition, a mentoring program should be in place to assure that each individual is appropriately guided and has an optimum chance for success. What do new faculty members, who are a year or two into their careers, need to know about the tenure-granting process? In order to be retained, tenured and promoted, an individual must have a clear idea of what is expected by the department and the school. "There should be a close match between an individual faculty member's personal career goals and objectives and those of the university's research and service program" (Dutton \& Addy, 1986, p. 660).

\section{Purpose}

The purpose of this study was twofold: to identify the factors that aid in the retention of Industrial Technology faculty at institutions of higher education; and to determine which factors are the important requirements in Industrial Technology programs. A review of available, related literature indicated that no research has been conducted relevant to retention factors that are specific to Industrial Technology. Understanding the various factors that aid in the retention, tenure and promotion of Industrial Technology faculty could meet the following goals:

- Provide specific data concerning retention to Industrial Technology institutions and administrators, and current and prospective employees.

- Facilitate the recruitment and retention of prospective and current faculty by identifying that factors that aid in determining if there is a match or mismatch between an individual faculty member's goals and those of the service programs.

- Provide a body of literature for further study in the area of retention, tenure and promotion. 


\section{Methodology}

This study was designed to identify relevant factors that aid in the retention of Industrial Technology faculty. The Delphi technique was chosen as the most appropriate methodology. This technique is valuable for reaching a consensus on topics such as those addressed in this study. The Delphi technique ensures anonymity while enabling each respondent to be more thoughtful, creative and without bias in his or her responses. Using several rounds of questionnaires, experts selected to participate in the study individually speculated and reached consensus collectively by rating factors based upon the results of their revised opinion.

Seventeen chairpersons of National Association of Technology (NAIT)-accredited Industrial Technology departments were randomly selected as experts using the current National Association of Industrial Technology Institutional Directory. Two of them dropped out during the project, resulting in an $88.2 \%$ response rate. There were four rounds of correspondence with the participants.

First Round. The initial questionnaire, requesting a list of factors that aid in the retention of Industrial Technology (IT) faculty at institutions of higher education, was sent to the respondents along with a cover letter explaining the purpose and importance of the study. In this round, each chairperson submitted a minimum of 16 items considered to be relevant factors in the retention of IT faculty. The items were organized by topic area which allowed the experts to conduct subsequent reviews and ratings in a systematic and efficient manner.

Second Round. All factors were consolidated and rewritten. Then they were returned by facsimile to the respondents for verification as to a clear, accurate expression of each chairperson's opinion. 
Third Round. The list was sent by facsimile to the respondents for rating purposes. The factors were rated using the following Likert-type scale: 1 = least important; 2 = very low in importance; 3 = moderately important; 4 = highly important; and $5=$ very highly important. The data collected were then analyzed using descriptive statistics to determine the mean score and standard deviation of the variables rated by the experts.

Fourth Round. The experts were asked to rate each item a second time, and then to adjust their score if their initial rating deviated more than two points for the item mean rating that was reported in round three. A final item mean analysis was calculated, which concluded the fourth and final round of the study.

\section{Findings and Discussion}

An analysis of the data revealed several important trends in promotion and tenure as perceived by IT department chairpersons. Five factors were considered: (a) Institutional related factors; (b) College/School related factors; (c) Departmental related factors; (d) Faculty related factors; and (e) Other related factors.

Institutional related factors. Table 1 exhibits the institutional related factors that were perceived to aid in the retention of IT faculty. The top two factors have means of 4 and above and fall into the category of highly important: promotion and retention policies $(4.55)$, and recognition for accomplishment (4.25). This finding is interesting in light of the fact that most institutional promotion and retention policies are criticized as being either ambiguously or vaguely worded. This sends forth a clear message that prospective faculty should seek written clarification of unclear policies. The next nine items fall into the moderately important category. 
They comprise 64 percent of the factors in this category, and serve to complement the first category and help faculty members clarify the essential tenure factors they must consider for personal achievement (Table 1).

Factors perceived to be of low importance for tenure were: affirmative action, service opportunity, and research opportunities. This finding suggests that faculty should not pay too much emphasis on these factors as they work toward tenure. Again, it is important to clarify that the research component of these factors may relate to NAIT-accredited but not research-based universities.

College/School related factors. The top four factors (36\%) in this category, challenging work environment, promotion and retention policies, recognition for achievement, and college leadership, were perceived as highly important variables in the retention of IT faculty (Table 2). The message here is that a lack of recognition of IT faculty for their achievements might be counterproductive to the college, school, and/or the department. Conflicts in leadership at all levels of an institution can indirectly spell trouble for faculty and their departments. The remaining seven factors (64\%) are of moderate importance and suggest a need for professional growth and development for faculty. This suggests that schools that do not promote and encourage the development of their faculty may be a disservice to both the faculty and the students.

Department related factors. All the factors in this category are either highly or moderately important in the retention of IT faculty (Table 3). When clustering and prioritizing the 11 highly important factors, the appearance of perception of job security, promotion and retention policies, and department leadership style in the first cluster suggest an apparent desire 
for a concrete leadership style. The second cluster includes the factors of student help, challenging work environment with collegial support, academic freedom, lab/classroom/office facility, and organization climate. These factors suggest that attention to the work environment and facilities is important. The final cluster includes strong connection with industry and opportunities for consultantships, high quality graduates to stimulate challenging thought, program content and philosophy, and progressive faculty. The high importance of these factors points to the need for opportunities for intellectual stimulation.

The eight factors ranked as moderately important are: provision for continuous professional development, mentoring opportunity, sabbatical opportunity, reasonable class load, strong secretarial and technical support, research opportunities, support opportunity for grants and contracts, and program accreditation. Collectively, these factors suggest the need for personal support for the faculty.

Faculty related factors. As shown in Table 4, one-third of the 18 factors fall into the category of highly important and the remaining two-thirds in the moderately important category. The appearance of the factors of job satisfaction; technical or professional expertise subject area; commitment to the position; service to the department, college and university; relationship to student as an advisor or mentor, and advanced terminal degree required as highly important factors suggests that IT faculty need to be satisfied in their work roles in order to exhibit a high degree of commitment to the position and the profession. In turn, faculty who are well chosen and qualified to perform their work roles will be of service to the department, college and university. The remaining 12 factors fall into the moderately important category, which suggest it is necessary to give faculty the opportunity and support needed to grow professionally. 
Other related factors. In the final group of 18 factors relating to promotion and tenure, 7 are highly important, 10 are moderately important, and 1 is very low in importance. The highly important factors, salaries and benefits, lab/classroom/office facilities, cost of living, recognition for accomplishment, community "feeling”, high quality graduates to stimulate and level of thought, and crime rate in the area, strongly and collectively suggest that although faculty members are concerned about their personal well being and satisfaction on the job, they are also concerned about the quality of life in the surrounding community. Personal satisfaction on the job is necessary for faculty members to perform their work adequately and meet their professional requirements. However, the relative importance of personal factors in this category implies that faculty are also concerned about their ability to enjoy life in the community.

The 10 factors in the moderately important category also suggest a concern by faculty about factors that affect their families as well as themselves. Good school systems for the children, affordable housing, opportunity for a spouse to find employment and a high profile department with a positive community image will certainly entice faculty to seek and become committed to a school and the community. It appears, however, that the location of the institution is not as important in promotion and retention issues as are finding a good place to live and work.

\section{Conclusion}

Faculty recruitment goals should work towards faculty tenure and promotion. It is counterproductive to recruit faculty members who seem tenurable and promotable at the time of their hiring but who do not eventually become tenured and promoted. The inference drawn from this study is that several factors contribute to the retention of a faculty member. While all of the 
factors listed may not be present in a particular institution, efforts should be made by the employing institution to put in place a system that will guarantee optimum support of tenure track faculty.

The implementation of promotion and tenure practices can be viewed as a joint activity for junior and senior faculty members. Bjorkquist (1988) emphasized that faculty who are seeking to be tenured or promoted need the support of all their colleagues as they proceed through a process that could potentially become a demeaning exercise.

Tenure and promotion are relatively long-range goals, and the immediate supervisor can help to set intermediate goals as incentives for the new faculty member. The supervisor is in a position to observe and assist the junior faculty member to maintain the level of motivation needed to succeed in the job. Mutual commitments between the employer and faculty member need to be maintained by the supervisor to prevent demotivation of the faculty member.

Professional associations are challenged to recommend standards of scholarship for the field and to provide outlets for creativity. This is of high importance among the many facilitating roles that a professional association can fill. Tenure and promotion are not the ultimate ends to be achieved. They are a means for protecting the freedom to search for truth and to recognize academic accomplishment (Bjorkquist, 1988). This is contrary to the widely held belief that tenure and promotion are a means to an end in itself rather than the protection of academic freedom.

\section{Recommendations}

Prospective tenure track faculty members should be aware of the factors cited in this study. Because the respondents in this study were a random sampling of IT department 
chairpersons, this list could serve as an important guide to persons considering tenure and promotion. Finally, this study could be replicated with both tenured and tenure track faculty responding to the questionnaire developed for the current study. As the current study used department chairpersons as the respondents, it would be interesting to note any similarities or disparity between the ratings of the two groups of respondents. 


\section{References}

Bjorkquist, D. C. (1988). Tenure and promotion in the 80s: Implications for the profession. Journal of Industrial Teacher Education, 21(2), 60-69.

Blackburn, R. T., O'Connell, C., \& Pellino, G. (1980). Evaluating faculty performance. In P. Jedamus, \& M. W. Peterson (Eds.), Improving academic management: A handbook of planning and instructional research. San Francisco: Jossey-Bass.

Bowen, H. R., \& Schuster, J. H. (1986). American professors: A national resource imperiled. New York: Oxford University Press.

Bowman, C. C. (1988). The college professors in America. New York: Amo Press.

Duff, J. M. (1988). Tenure and promotion: A response. Journal of Industrial Teacher Education, 25(2), 70.

Dutton, J. C., \& Addy, A. L. (1986). Clearing the hurdles along the tenure track. Engineering Education, 63(5), 660-663.

Jones, M. S., Casali, J. F., \& Greene, T. J. (1985). Criteria for selecting a university position. Engineering Education, 75(7), 624-628.

Israel, E. N., \& Baird, R. J. (1988). Tenure and promotion: Changing expectations and requirements, Journal of Industrial Technology, 25(2), 16-21.

Kasten, K. L. (1984). Tenure and merit pay as rewards for research, teaching, and service at a research university. Journal of Higher Education, 55, 500-504.

Lokensgard, E. (1989). Representation of minorities and women on industrial and engineering technology faculties. Journal of Industrial Technology, 5(2), 13-15.

Miller, P. W. (1988). Tenure and promotion: The need for good decisions. Journal of Industrial Teacher Education, 25(2), 3.

Sanders, M. (1988). Tenure and promotion process: A case study analysis. Journal of Industrial Teacher Education, 25(2), 48-59. 
Table 1. Institutional related factors

\begin{tabular}{lll}
\hline Variable & Mean & S.D. \\
\hline Promotion and retention policies & 4.55 & 0.68 \\
Recognition for accomplishment & 4.25 & 0.86 \\
Provision for continuous professional development & 3.82 & 0.83 \\
Progressiveness in administration & 3.73 & 0.75 \\
Academic freedom & 3.64 & 0.88 \\
Institutional leadership & 3.64 & 0.98 \\
Organizational climate & 3.55 & 0.89 \\
Strong connection with industry, ample opportunity for consultantship & 3.55 & 0.78 \\
Opportunity for advancement & 3.45 & 0.78 \\
Support and opportunity for grants and contracts & 3.36 & 9.88 \\
Mentoring opportunity & 3.00 & 9.85 \\
Affirmative action policies & 2.91 & 1.24 \\
Service opportunity & 2.73 & 0.75 \\
Research opportunities & 2.64 & 1.24 \\
\hline
\end{tabular}

Key: 1=least important; $2=$ very low importance; $3=$ moderately important; $4=$ highly important; $5=$ =very important. 
Table 2. College/School related factors

\begin{tabular}{lcc}
\hline Variable & Mean & S.D. \\
\hline Challenging work environment with collegial support & 4.55 & 0.66 \\
Promotion and retention policies & 4.36 & 0.77 \\
Recognition for achievement & 4.27 & 0.75 \\
College leadership style & 4.00 & 0.85 \\
Academic freedom & 3.91 & 0.79 \\
Provision for continuous professional development & 3.91 & 0.79 \\
Department with a high profile and positive image in the community & 3.91 & 0.79 \\
Strong connection with industry with ample consultantships & 3.55 & 0.89 \\
Support \& opportunity for grants and contracts & 3.45 & 0.78 \\
Research opportunities & 3.27 & 1.21 \\
Opportunity for advancement & 3.27 & 0.86 \\
\hline
\end{tabular}

Key: 1=least important; 2=very low importance; $3=$ =moderately important; 4=highly important; 5=very important. 
Table 3. Departmental related factors

\begin{tabular}{lcc}
\hline Variable & Mean & S.D. \\
\hline Perception of job security & 4.45 & 0.66 \\
Promotion and retention policies & 4.45 & 0.89 \\
Departmental leadership style & 4.27 & 0.62 \\
Student help & 4.18 & 0.94 \\
Challenging work environment with collegial support & 4.09 & 0.51 \\
Academic freedom & 4.09 & 0.51 \\
Lab/classroom/office facilities & 4.00 & 0.95 \\
Organizational climate & 4.00 & 0.85 \\
Strong connection with industry, opportunities for consultantships & 4.00 & 0.74 \\
High quality graduates to stimulate challenge, thought & 4.00 & -0.60 \\
Program content and philosophy & 4.00 & 0.74 \\
Progressive faculty & 4.00 & 0.60 \\
Provision for continuous professional development & 3.91 & 0.67 \\
Mentoring opportunity & 3.91 & 0.90 \\
Sabbatical opportunity & 3.91 & 1.24 \\
Reasonable class load & 3.73 & 0.62 \\
Strong secretarial and technical support & 3.64 & 0.64 \\
Research opportunities & 3.55 & 1.08 \\
Support and opportunity for grants, contracts & 3.55 & 0.78 \\
\hline Program is accredited & 3.36 & 0.77 \\
\hline
\end{tabular}

Key: $1=$ least important; $2=$ =ery low importance; 3 =moderately important; 4=highly important; $5=$ =very important. 
Table 4. Faculty related factors

\begin{tabular}{lcc}
\hline Variable & Mean & S.D. \\
\hline Job satisfaction & 4.55 & 0.50 \\
Technical or professional expertise, subject area & 4.27 & 0.62 \\
Commitment to the position & 4.18 & 0.72 \\
Service to the department, college, university & 4.18 & 0.72 \\
Relationship to student as an advisor or mentor & 4.18 & 0.72 \\
Advanced terminal degree required & 4.09 & 0.79 \\
Excellence and growth in teaching & 3.91 & 0.67 \\
Teamwork & 3.67 & 0.86 \\
Teaching effectiveness & 3.64 & 0.48 \\
Willingness to assume responsibility & 3.64 & 0.48 \\
Demonstrated scholarly achievement in subject area & 3.64 & 0.98 \\
Provision for continuous professional development & 3.64 & 0.64 \\
Curriculum and instruction materials development & 3.55 & 0.66 \\
Publication, presentation, professional involvement in associations & 3.55 & 0.66 \\
Opportunity for advancement & 3.37 & 0.62 \\
Program for stability & 3.18 & 0.94 \\
Progressiveness in administration & 3.09 & 0.79 \\
Service opportunity & 3.00 & 1.04 \\
\hline
\end{tabular}

Key: 1=least important; 2=very low importance; $3=$ =moderately important; 4=highly important; 5=very important. 
Table 5. Other related factors

\begin{tabular}{lll}
\hline Variable & Mean & S.D. \\
\hline Salaries and benefits & 4.55 & 0.50 \\
Lab/classroom/office facilities & 4.36 & 0.77 \\
Cost of living & 4.27 & 0.75 \\
Recognition for accomplishment & 4.00 & 0.85 \\
Community "feeling" & 4.00 & 0.74 \\
High quality graduates to stimulate and level of thought & 4.00 & 0.60 \\
Crime rate in area & 4.00 & 0.72 \\
Adjustment of an individual into an academic community & 3.82 & 0.83 \\
Program stability & 3.73 & 0.62 \\
Demand for graduates & 3.73 & 0.62 \\
Student help & 3.64 & 1.23 \\
Program has good enrollment & 3.64 & 1.23 \\
Availability of job for spouse & 3.64 & 0.88 \\
Secondary school quality & 3.55 & 1.08 \\
Housing availability & 3.55 & 1.08 \\
Department with high profile and positive image in community & 3.36 & 0.48 \\
Students' perception of instructor, instruction and administration & 3.27 & 1.05 \\
\hline Location & 2.82 & 0.83 \\
\hline
\end{tabular}

Key: 1=least important; 2=very low importance; 3=moderately important; 4=highly important; $5=$ very important. 